\title{
Educação a distância em um curso de pós-graduação lato sensu na área de Administração: um relato de pesquisa
}

Luis Roque Klering - PPGA/UFRGS - lrklering@via-rs.net

Alexandra Jochims Kruel - PPGA/UFRGS - ajkruel@ea.ufrgs.br

Christine da Silva Schröeder - PPGDR/UNISC - christine@ unisc.br

Lucas Casagrande - PPGA/UFRGS e UERGS - lcasagrande@gmail.com

\section{Resumo}

Este estudo buscou acessar e compreender a percepção de estudantes de um curso de pós-graduação lato sensu de grande porte (com mais de 600 alunos iniciais), na área de Administração, de uma universidade pública do sul do Brasil, oferecido na modalidade a distância. Os dados foram obtidos por meio de questionários com questões abertas e fechadas, enviados e respondidos no próprio ambiente virtual de aprendizagem/AVA, e analisados pela técnica de análise de conteúdo. Os principais resultados do estudo apontam para a necessidade de superação dos seguintes desafios: melhorar as tecnologias e soluções administrativas e pedagógicas, definir melhor as estratégias de realização das monografias e estabelecer atitudes e papeis mais adequados (para os atores do processo de aprendizagem) ao novo contexto educacional, dentre outros.

Palavras-chave: educação a distância, pós-graduação lato sensu, percepções.

Distance education in a postgraduate course in the area of Administration: a report of research

\begin{abstract}
This study aims to understand the students' perception of a postgraduate course (with more than 600 students), in the area of Administration, of a public university of the south of Brazil, in distance education. The data were obtained through questionnaires, sent and answered in the virtual environment of learning, and analysed by analysis of content. The principal results point to the necessity of overcoming of the next challenges: to improve the technologies and administrative and pedagogic solutions, to define better the strategies of development of the monographs and to establish attitudes and more appropriate functions (for the actors of the process of learning) to the new education context, among others.
\end{abstract}

Keywords: distance learning; postgraduate course; perceptions.

\section{Introdução}

A forte competitividade no mercado de trabalho torna necessária uma contínua e crescente qualificação dos profissionais, o que faz dos cursos de pós-graduação um requisito cada vez mais valorizado neste mesmo mercado. Dessa forma, a educação a distância (EAD) desponta como uma possibilidade para que cada vez mais pessoas tenham acesso ao ensino, dada sua maior penetrabilidade geográfica em um país, especialmente daqueles que têm territórios grandes e de difícil acesso, em comparação com a modalidade de educação presencial. A modalidade também permite a interessados terem acesso a cursos e professores mais qualificados, contatos com colegas de outras localidades e regiões, com estudos em horários mais flexíveis, e normalmente a custos menores. Sendo assim, a EAD traz ao ensino, sobretudo ao ensino 
superior em nível de pós-graduação, alguns desafios e potencialidades a serem explorados, como uma nova forma de se obter conhecimento e qualificação profissional.

Assim, acredita-se que, tanto para a academia quanto para as organizações, pesquisas e reflexões acerca desta modalidade se fazem constantemente necessárias, a fim de que, conhecendo-a melhor, as instituições de ensino, em especial as de ensino superior, possam implementá-la de forma qualificada, proporcionando assim um processo de ensino-aprendizagem de qualidade, que possibilite a tão requerida preparação profissional, nos mais diferentes segmentos. É esta a reflexão que este artigo se propõe a trazer. A partir, então, da análise das percepções de alunos de um curso de pós-graduação lato sensu de grande porte (com mais de 600 alunos iniciais), na área de Administração, de uma universidade pública do sul do Brasil, oferecido na modalidade a distância, apresenta-se este relato de pesquisa, seus principais resultados e considerações. Para tanto, parte-se de um breve referencial teórico sobre sociedade da informação, educação a distância, distância transacional e construtivismo.

\section{Sociedade da Informação}

A chamada sociedade da informação deriva da Revolução Tecnológica, iniciada na década de 1980, na qual a informação adquiriu um caráter de bem de produção, em um processo moldado - não exclusivamente - pelas lógicas e interesses capitalistas, e para cujo modo de produção Castells (1999) utiliza o conceito de informacionalismo.

Sob esta perspectiva, crê-se que existe efetivamente uma revolução em curso (Castells, 1999; Toffler, 1995; Tapscott, 1997), tanto em nível produtivo como também nas esferas sociais e individuais. Neste contexto, no final do século XX, o conhecimento tornou-se o fundamento essencial das tecnologias de informação e comunicação, estas baseadas nos meios de comunicação de massa e nas redes eletrônicas. Os computadores, como instrumentos essenciais destas tecnologias, descentralizam a informação e o conhecimento, tornando-os acessíveis a milhões de pessoas, independentemente de localização geográfica.

Mas se, por um lado, há um constante incremento tecnológico a favor da expansão da informação e do conhecimento, por outro, entende-se que a forte competitividade no mercado de trabalho torna necessária uma crescente qualificação dos profissionais, especialmente daqueles com nível superior, o que faz da pósgraduação um requisito cada vez mais valorizado neste mesmo mercado. Neste contexto, surge a figura do curso de especialização a distância mediado pela internet.

\section{Educação a Distância: potencialidades e desafios}

A educação a distância/EAD é um processo de ensino-aprendizagem, mediado pela tecnologia, no qual professores e alunos podem se encontrar em diferentes lugares ao mesmo tempo (Moran, 2002), e se pressupõe que o controle sobre o aprendizado é feito mais pelo aluno que pelo professor (Tarouco, 1999). A definição do termo parte do pressuposto de que a informação, tal como fonte do conhecimento, se encontra separada do professor e/ou do estudante em tempo e/ou espaço. Assim, Cardoso e Pestana (2001) definem dois meios para a EAD: o unidirecional - composto de um único sentido da via para a transmissão do material para o estudante; e o bidirecional - composto de uma via de mão-dupla, utilizada tanto para a informação do estudante, quanto para a interação entre ele e o professor. Por tais motivos, o conceito aqui utilizado será predominantemente o de educação a distância, já que o termo ensino tende a sobrepujar o controle do professor em detrimento do controle do próprio estudante.

A EAD não é algo novo. Antes da internet, ela era mediada por outros instrumentos, como os serviços de correio, vídeos, fitas $\mathrm{K} 7$, e foi vista, durante muito 
tempo, como uma espécie de "estepe" do ensino, a que se recorria quando o ensino tradicional "não dava conta". Azevedo (2000) afirma que a sociedade se acostumou a olhar para a EAD como uma espécie de educação inferior, utilizada por excluídos, geográfica ou socialmente, tendo dentre suas causas a linguagem mais acessível e o formato dos programas, disseminados pelos meios de comunicação de massa, dando uma visão de que a educação a distância era "coisa de pobre". No entanto, com a chegada da internet e seu uso progressivo na EAD, esta última vem adquirindo uma conotação cada vez mais positiva, impulsionada pelo fator novidade, com melhorias nas soluções disponibilizadas e na tecnologia de suporte, acrescido de fortes investimentos de renomadas universidades públicas, privadas e corporativas.

Para Palloff e Pratt (2002), a EAD mediada pela tecnologia da internet corresponde a um novo espaço para que os estudantes possam explorar o conteúdo dos cursos de forma colaborativa e buscar seus interesses. Kramer et al (1999), por sua vez, salientam que a educação a distância pode resolver, se aplicada de modo sistemático e coordenado, a carência de oferta de estudos para os brasileiros. Ainda em termos de vantagens intrínsecas da EAD, Klering e Schroeder (2008) elencam: o ganho de escala; as possibilidades de acervo de materiais em formato digital, de forma mais organizada e prática de consultar; o desenvolvimento próprio de materiais de ensino; as possibilidades de materiais de aprendizagem multimídia; apoio constante à educação, não se restringindo a poucas horas diárias, como no ensino presencial; e a maior autonomia dos alunos a partir de horários e espaços mais livres.

Em termos de estrutura, há necessidade de aquisição e instalação de softwares, hardwares e linhas de telecomunicação, bem como uma necessidade de possibilitar o fácil manuseio dos mesmos (Palloff; Pratt, 2002), algo que inicialmente pode ser mais oneroso. Superados os desafios de nível estrutural, Klering, Biancamano e Guadagnin (2004) apontam, em termos pedagógicos, para a necessidade de promover a atratividade dos conteúdos; do desenvolvimento de um espírito de comunidade; do desenvolvimento de um código cultural próprio para a consolidação do espírito de comunidade e de pertencimento a um grupo; e do uso da avaliação como instrumento de aprendizagem.

\section{Distância transacional e construtivismo como conceitos importantes}

A separação espacial e por vezes temporal gerada pela EAD altera consideravelmente o processo de ensino-aprendizagem. No entanto, a qualidade da educação na EAD não deve ser medida em termos de tempos e espaços síncronos e compartilhados, mas sim avaliada sob a concepção de distância transacional, que nos remete à distância relevante na qual os atores estão envolvidos, e não à distância física. Ela diz respeito a dificuldades de interação e autonomia e, na medida em que seu grau aumenta, tende a prejudicar o processo de ensino-aprendizagem (Moore, 1993).

Conforme Maia e Mattar (2007), a distância transacional pode ser avaliada sob três variáveis: a) interação, em que a natureza das mídias utilizadas influi diretamente na quantidade e qualidade do diálogo que se estabelece entre professores e alunos; b) estrutura do programa: em que o projeto do curso influencia diretamente a distância transacional; c) autonomia do estudante: necessária para o diálogo, mas que não pode ser considerada central. Assim, um curso com alto grau de autonomia dos estudantes e de interação dos atores envolvidos, além de estruturado de forma aberta, pode apresentar uma distância transacional inferior ao de cursos presenciais, na medida em que os atores possam se relacionar mais livremente, sejam mais autônomos e tenham voz dentro do curso, o que parece coerente com a perspectiva construtivista.

Para Loyolla e Prates (2001), existem três grandes correntes teóricas em uso: o comportamentalismo, o cognitivismo e o construtivismo. O primeiro foi amplamente 
utilizado no ensino primário até meados do século $\mathrm{XX}$, e consistia basicamente na exposição repetida do professor sobre o conteúdo da aula, alheio às condições dos alunos, somado a um fator motivacional dirigido por prêmios ou castigos. A segunda corrente teórica é o cognitivismo. Sob esta ótica, o professor expõe o conteúdo da aula com uma preocupação de explicar os fundamentos do objeto de ensino em questão, mas tal corrente ainda parte do pressuposto de que os alunos aceitam passivamente o conteúdo e que o professor é uma espécie de "ser iluminado" que os guia.

No construtivismo, por sua vez, o foco está no estudante e seu aprendizado, ou seja, a tônica deixa de ser o professor e passa a ser o aluno. Tal característica segue os preceitos de Piaget $(1973 ; 1976 ; 1977)$ e Vygotsky (1987; 1988). Segundo tal concepção, o conhecimento não mais é compreendido como um conteúdo ou produto, mas sim como um processo, no qual se constrói o próprio sujeito a partir das interações.

\section{A pesquisa}

A pesquisa foi realizada com alunos de um curso de pós-graduação lato sensu, realizado em caráter piloto, por uma universidade pública no sul do Brasil, por meio de uma parceria entre a referida universidade e uma universidade corporativa de uma sociedade de economia mista. A atuação desta parceria, cuja intenção era promover a capacitação daqueles interessados em desenvolver carreira como gestores, atingiu os três Estados da região sul do Brasil, e contou com mais de seiscentos alunos.

O curso foi estruturado por módulos temáticos, com conteúdos interativos, uso de material multimídia (principalmente de vídeos digitais gerados e apostilas eletrônicas desenvolvidas para cada disciplina), tendo a internet como intermediadora para a comunicação e uma plataforma criada e desenvolvida pela Universidade, com a intenção de apoiar os processos de aprendizagem, tanto nas áreas de ensino quanto de pesquisa e extensão, por meio das interações virtuais. A plataforma utilizada foi a Plataforma NAVi, desenvolvida a partir de experiências de educação a distância junto à Escola de Administração da Universidade Federal do Rio Grande do Sul. A NAVi se caracteriza por: dar ênfase à interação; ter um enfoque sistêmico; basear-se no princípio da simplicidade de navegação; dar autonomia de atualização de material aos professores. Ela possibilita disponibilizar aos estudantes diversos recursos, com o intuito de aumentar ao máximo o grau de interesse destes, como enquetes, aulas interativas (chats), fóruns de discussões aprofundadas, exercícios online, avaliações, portfólios, estudos de caso e relatos, suporte técnico, café virtual, correio interno, indicadores de controle dos acessos, e outros.

No curso, os estudantes foram acompanhados por tutores, em um processo ativo, embasado em uma orientação construtivista, tendo como meios para sua concretização a referida plataforma e um suporte técnico por e-mail e telefone para o esclarecimento de dúvidas acadêmicas e técnicas. As disciplinas foram conduzidas por professores-autores e apoiadas por tutores (um coordenador de tutores e um tutor por turma, constituindo cada turma um grupo de até 35 alunos, reunidos virtualmente e nas reuniões presenciais ao redor de um polo (cidade) de referência, num total de 15 polos, nos três Estados do sul do Brasil).

Primeiramente, foram realizados estudos bibliográficos e de fontes documentais que permitissem compreender o contexto institucional e do curso; posteriormente, então, realizou-se coleta de dados por meio da aplicação de um questionário de avaliação institucional, pelo qual se procurou obter as percepções dos estudantes acerca do curso realizado. Os questionários foram disponibilizados na plataforma, ao final do curso, para todos os estudantes que completaram sua formação. Foram respondidos 179 questionários. A análise dos dados se fez em dois momentos: o primeiro, a partir de uma 
análise estatística inferencial das respostas fechadas; e o segundo, foco deste artigo, por análise de conteúdo (Bardin, 1977), a partir das respostas às questões abertas.

\section{Os resultados}

A análise de conteúdo gerou três categorias principais, por meio de um processo de derivação de quinze categorias iniciais (ver Quadro 1), as quais emergiram dos questionamentos feitos aos estudantes sobre aspectos que eles consideraram positivos e negativos no curso, bem como das razões que os levariam a indicar ou não o curso para outras pessoas, das razões que os levariam ou não a realizar outro curso de pósgraduação na universidade estudada, e das sugestões que dariam ao curso.

\section{Quadro 1 - Quadro-síntese de categorias iniciais e finais}

\begin{tabular}{|c|c|c|c|}
\hline \multicolumn{2}{|c|}{ CATEGORIAS INICIAIS } & \multicolumn{2}{|c|}{ CATEGORIAS FINAIS } \\
\hline $\begin{array}{c}\text { 1. Aspectos } \\
\text { tecnológicos: } \\
\text { plataforma de EAD }\end{array}$ & $\begin{array}{l}\text { Sensações e experiências dos estudantes com a } \\
\text { plataforma de EAD, helpdesk, bem como com a criação } \\
\text { de novas formas de interação entre os estudantes para } \\
\text { resolver dificuldades de interação. }\end{array}$ & \multirow{4}{*}{$\begin{array}{c}\text { A } \\
\text { Educação a } \\
\text { distância e } \\
\text { plataforma de } \\
\text { EAD }\end{array}$} & \multirow{4}{*}{$\begin{array}{l}\text { Relativo à plataforma, seu } \\
\text { suporte, seus espaços de } \\
\text { interação virtual (chats, } \\
\text { fóruns, café virtual) e a } \\
\text { evolução do sistema durante } \\
\text { o decorrer do curso. } \\
\text { Em tal categoria final estão } \\
\text { inclusos os diferenciais do } \\
\text { sistema de EAD frente ao } \\
\text { presencial, tais como a } \\
\text { liberdade de horário, a } \\
\text { praticidade e a necessidade de } \\
\text { autodisciplina. }\end{array}$} \\
\hline $\begin{array}{l}\text { 2. Espaços de } \\
\text { interação virtual }\end{array}$ & $\begin{array}{l}\text { Aspectos relativos aos espaços de interação virtual, } \\
\text { como chats, fóruns e café virtual, bem como o uso } \\
\text { destes. }\end{array}$ & & \\
\hline $\begin{array}{l}\text { 13. Facilidades de } \\
\text { estudo }\end{array}$ & $\begin{array}{l}\text { Aspetos relativos à liberdade de horário e à facilidade } \\
\text { de acesso ao sistema virtual, gerando eficiência de } \\
\text { tempo e de custos. }\end{array}$ & & \\
\hline 14. Autodisciplina & $\begin{array}{l}\text { Aspectos relativos à necessidade de autodisciplina, } \\
\text { atuação individual e pró-ativa. }\end{array}$ & & \\
\hline $\begin{array}{l}\text { 3. Relacionamento } \\
\text { com a Universidade }\end{array}$ & 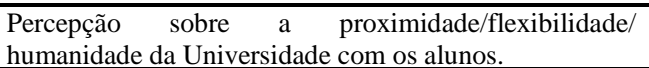 & \multirow{8}{*}{$\begin{array}{l}\text { Organização } \\
\text { do Curso }\end{array}$} & \multirow{8}{*}{$\begin{array}{l}\text { Categoria final referente à } \\
\text { percepção dos estudantes } \\
\text { quanto à organização e } \\
\text { andamento do curso, a } \\
\text { relação entre a coordenação e } \\
\text { os estudantes, o conteúdo, o } \\
\text { material didático e a a } \\
\text { condução das disciplinas, } \\
\text { além da importância do curso } \\
\text { para impactar sobre o } \\
\text { curriculum vitce. }\end{array}$} \\
\hline 7. Material Didático & 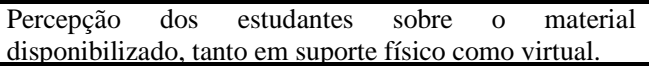 & & \\
\hline 8. Conteúdo & $\begin{array}{l}\text { Percepção sobre o conteúdo das disciplinas: quantidade, } \\
\text { qualidade, aplicabilidade. }\end{array}$ & & \\
\hline $\begin{array}{l}\text { 9. Condução de } \\
\text { disciplinas }\end{array}$ & $\begin{array}{l}\text { Aspectos relativos à condução das disciplinas, como } \\
\text { trabalhos em grupos, exercícios online, avaliações e } \\
\text { recuperação. }\end{array}$ & & \\
\hline 10. Monografia & $\begin{array}{l}\text { Aspectos sobre a monografia, especialmente relativos a } \\
\text { problemas e orientações. }\end{array}$ & & \\
\hline $\begin{array}{l}\text { 11. Planejamento do } \\
\text { currículo }\end{array}$ & $\begin{array}{l}\text { Aspectos relativos ao programa do curso e à } \\
\text { sequenciação das disciplinas, conforme o plano do } \\
\text { curso. }\end{array}$ & & \\
\hline $\begin{array}{l}\text { 12. Aspectos } \\
\text { organizativos }\end{array}$ & $\begin{array}{l}\text { Percepções sobre a organização e a estrutura do curso, } \\
\text { referindo-se a regras, prazos e preparo dos tutores e } \\
\text { professores. }\end{array}$ & & \\
\hline $\begin{array}{l}\text { 15. Qualificação do } \\
\text { currículo }\end{array}$ & $\begin{array}{l}\text { Aspectos relativos ao prestígio do nome da } \\
\text { Universidade, dando maior peso ao currículo pessoal } \\
\text { como motivação para fazer o curso. }\end{array}$ & & \\
\hline $\begin{array}{l}\text { 4. Interação entre } \\
\text { colegas }\end{array}$ & $\begin{array}{l}\text { Percepção das possibilidades de interação via encontros } \\
\text { presenciais e virtuais, potencializando as trocas de } \\
\text { experiências e informações entre estudantes de } \\
\text { diferentes regiões. }\end{array}$ & \multirow{3}{*}{$\begin{array}{l}\text { C } \\
\text { Interações e } \\
\text { atuações }\end{array}$} & \multirow{3}{*}{$\begin{array}{l}\text { Interação entre colegas e } \\
\text { colegas, entre estudantes e } \\
\text { tutores, e entre estudantes e } \\
\text { professores-autores. }\end{array}$} \\
\hline 5. Professores-tutores & $\begin{array}{l}\text { Percepção do papel dos tutores no processo de } \\
\text { aprendizagem dos alunos; seu preparo, dedicação, } \\
\text { comnrometimento }\end{array}$ & & \\
\hline 6. Professores-autores & $\begin{array}{l}\text { Percepção que os alunos têm dos professores, em } \\
\text { termos de conhecimento dos assuntos } \\
\text { comprometimento com o processo de aprendizagem. }\end{array}$ & & \\
\hline
\end{tabular}

Fonte: Dados da pesquisa.

Em relação à categoria final $\mathbf{A}$ - Educação a distância e plataforma de EAD, esta compõe-se de questões relativas:

a) aos aspectos tecnológicos da plataforma de EAD adotada, incluindo-se as impressões dos estudantes, o suporte do helpdesk e a criação de novas formas de interação. De acordo com a percepção dos estudantes, no decorrer do curso houve um 
progressivo aumento da qualidade da plataforma que, criada há vários anos, em 1998, vem sendo desenvolvida e aprimorada constantemente. O helpdesk, que deveria dar suporte para os usuários, também deixou a desejar no início, pela demora em responder a demandas. No decorrer do curso, a atuação do helpdesk passou a ser considerada de forma positiva, assim como a facilidade de acesso à plataforma, ou seja, sua portabilidade. Interessante foi que, em função das dificuldades, os estudantes procuraram formas alternativas de relacionamento e interação virtuais (basicamente por e-mails externos à plataforma, aplicativos de mensagens instantâneas, como $M S N$ e $I C Q$, e sites de relacionamentos).

b) aos espaços de interação virtual e seus usos (chats, fórum e café virtual). Essencialmente, o grande atributo da EAD, por meio da internet, é proporcionar alternativas de interação, especialmente via chats e fóruns. Os alunos perceberam claramente a intenção de cada espaço: os chats, entendidos como uma interação com menos foco e mais abrangente, mais fluida e menos organizada; e os fóruns, vistos como uma forma de interação mais focada, na qual há a possibilidade de se aprofundar nos assuntos. Embora alguns estudantes tenham apontado que esta ferramenta foi usada de forma superficial por vários colegas, é ali que realmente há a resolução de dúvidas e onde ocorrem os debates mais aprofundados e claros. Já o café virtual foi visto com certo desdém e mesmo desconfiança, não cumprindo sua finalidade de ser um espaço de descontração.

c) às facilidades de estudo, como acesso, redução de custos com deslocamentos e liberdade de horários para estudo, tornando possível aos alunos viajarem ou estudarem conforme sua própria disponibilidade de tempo, bem como terem pronto acesso aos acervos e materiais virtuais, sem se precisar recorrer a cópias, bibliotecas e livrarias.

d) à necessidade de autodisciplina e atuação individual e proativa. Ser aluno de EAD implica numa postura nova em termos de aprendizagem, uma atuação individual que envolva autocontrole, autoaprendizagem e autodesenvolvimento.

Já a categoria final B - Organização do curso refere-se às percepções dos alunos com relação ao curso em si, sua organização, estrutura, conteúdo e andamento. $\mathrm{O}$ curso em geral foi considerado desorganizado, mas os próprios respondentes justificaram esta realidade, alegando que se tratava de um curso sob uma nova modalidade, e, portanto, com muitos ajustes a se fazer. Esta categoria foi, então, assim analisada:

a) quanto ao relacionamento com a Universidade, foram feitas reclamações quanto ao distanciamento da Universidade - aspecto reforçado pelo distanciamento físico, visto que o curso é realizado em cidades-polo - e ao autoritarismo, inflexibilidade e falta de sensibilidade frente às demandas dos estudantes.

b) quanto aos aspectos organizativos do curso, parte dos estudantes considerou que houve falta de transparência nas regras, especialmente em relação à recuperação de conteúdos e avaliações, e à demora na divulgação de notas. Por outro lado, positivamente, foi salientado o alto nível de conhecimento de professores e tutores.

c) o planejamento do currículo do curso foi elogiado por ter sido seguido de forma que os alunos conseguissem organizar previamente sua agenda, e principalmente pela ocorrência de uma disciplina por vez, em que os alunos puderam se dedicar exclusivamente a cada uma. Entretanto, ao final do curso, houve sobreposição de disciplinas com a realização da monografia, e os alunos consideraram que isso reverteu em perda de qualidade do trabalho final. De outro lado, a inclusão de temas no currículo como responsabilidade socioambiental e ética foi elogiada por sua atualidade e pertinência. Todavia, para os estudantes, ainda houve pouco tempo para disciplinas fundamentais. 
d) em relação aos conteúdos, em termos gerais, as manifestações não foram consensuais: em termos qualitativos, enquanto alguns afirmaram que houve distância entre teoria e prática, outros elogiaram a pertinência do conteúdo e afirmaram que receberam ensinamentos que serão utilizados no dia-a-dia. Em termos quantitativos, houve aqueles que consideraram o conteúdo excessivo e não condizente com as horas de aula, os que o consideraram como insuficiente e os que o consideraram "na medida".

e) sobre o material didático, embora não tenha havido consenso nas respostas, em geral, este foi considerado pelos estudantes como sendo de alta qualidade. As queixas foram sobre a ocorrência de muitos erros não corrigidos no material; a quantidade nada enxuta do mesmo, perdendo em objetividade ao tentar tratar temas com maior profundidade e abrangência; e a falta de apostilas em suporte físico (papel). Também houve manifestações negativas quanto à organização interna das apostilas, como a ausência de sumários e o layout delas, considerado confuso. Já, como aspecto positivo, os estudantes elogiaram muito a facilidade de acesso ao material didático virtual.

f) a condução de disciplinas diz respeito à dinâmica. Os trabalhos em grupo foram considerados problemáticos, pois, mesmo pertencendo a um mesmo polo, os integrantes das equipes não necessariamente residiam na mesma cidade, fato que tornava mais difícil a realização de reuniões presenciais. Houve manifestações de alunos que sequer tomavam conhecimento das tarefas. Também contribuiu o fato de os tutores definirem os integrantes das equipes, e não os próprios estudantes. As críticas demonstraram que a plataforma de EAD adotada pelo curso estava pouco apta para dar suporte a trabalhos em grupo, o que poderia ser resolvido pela criação de alguma ferramenta para trabalhos coletivos, como um wiki (página virtual construída por meio de trabalho colaborativo) fechado a uma turma ou grupo de um curso, por exemplo. Mas, se por um lado falta tal funcionalidade na plataforma, por outro, os exercícios online foram considerados ótimos para facilitar a aprendizagem, mas não como ferramenta para avaliação. Os exercícios online facilitaram a compreensão dos conteúdos e, por haver retorno rápido aos alunos, tornaram o processo mais interativo e atrativo. Por outro lado, as avaliações presenciais (provas finais das disciplinas) foram apresentadas em quantidade demasiada e tempo insuficiente para sua realização. Os alunos criticaram também a necessidade de decorar conteúdos, a quantidade excessiva de conteúdo por prova, e o grande distanciamento de tempo entre as provas presenciais. A supervalorização dos chats e dos fóruns em detrimento das avaliações por meio de provas virtuais, no cômputo da nota final, também foi alvo de críticas. Sobre as recuperações de notas nas disciplinas, os estudantes manifestaram-se insatisfeitos, porque não estavam previstas, embora fossem necessárias.

g) em relação à monografia (trabalho final do curso), seu processo de orientação foi considerado desorganizado desde o seu início, em função do desdobramento da orientação em fases e pela indefinição quanto ao orientador efetivo. Os estudantes criticaram o fato de terem efetivamente sido orientados apenas por tutores, muitas vezes sem a devida assistência dos professores-orientadores formais, o que gerou uma percepção de falta de interação entre orientador e orientando, atribuída pelos estudantes a alguns fatores: 1) a um suposto desinteresse por parte de alguns professores-tutores (embora muitos tenham sido elogiados por sua atuação dedicada); 2) à falta de envolvimento mais direto de professores-orientadores e 3) à própria distância, em termos de espaço e de tempo de resposta aos seus questionamentos.

h) a possibilidade de qualificação do curriculum vitae foi referida. Os alunos, em geral, manifestaram satisfação em adquirirem conhecimentos, aprimoramento e titulação, por meio da formação em uma universidade muito bem conceituada, 
possibilitando que tornassem seu currículo mais atrativo e obtivessem pontuação em avaliações na própria instituição onde trabalham.

Em relação à categoria final $\mathbf{C}$ - Interações e atuações, foram detectadas duas posições divergentes: o argumento utilizado pela primeira opinião é que a escrita dificulta a interação, já que, no momento em que é preciso escrever para expressar algo, a comunicação torna-se menos fluida e mais artificial. Do lado oposto, outros alegaram que é positiva a possibilidade irrestrita de comunicação entre todos numa sala virtual, que claramente não ocorre numa sala de aula presencial, onde um estudante, por vez, normalmente debate com os colegas que estão fisicamente próximos. De forma geral, outros níveis de interação foram analisados:

a) A interação entre colegas diz respeito aos relacionamentos e responsabilidades entre os estudantes. Por um lado, vários se ressentiram dos poucos encontros presenciais. Por outro, muitos deles avaliaram que, justamente por ser um curso a distância, há uma maior troca de experiências, pois esta interação não se dá somente em uma cidade ou região, mas entre todas as cidades-polo. Merece ainda ser referida a tendência de estudantes isolarem-se do grupo, não se envolvendo com a construção coletiva da aprendizagem. Conforme as afirmações, isso seria consequência da autodisciplina e autossuficiência exigida pelo curso, mas mal interpretada por alguns estudantes, que se portaram de forma isolada nas atividades individuais, e que se mantiveram apáticos aos processos de interação.

b) Em relação à atuação dos tutores, os estudantes elogiaram bastante a atuação destes em relação à solicitude, à proatividade e ao interesse no progresso dos estudantes, trabalhando como orientadores de estudos. No entanto, muitos dos tutores foram considerados despreparados para a $\mathrm{EAD}$, em que pesaram aspectos relacionados à (má) condução dos chats, ao desnível de atuação entre eles, demonstrando uma clara necessidade de uma formação que os habilite previamente às necessidades do curso.

c) Em relação à atuação dos professores-autores, os alunos reconheceram e elogiaram o grau de conhecimento dos mesmos, classificando-os até mesmo com o termo "excepcional". Entretanto, os estudantes também manifestaram que vários dos professores-autores foram omissos e pouco atuantes no ambiente virtual, e que houve pouca interação deles com suas turmas e com seus os alunos durante o curso.

\section{Considerações finais}

A EAD possui características próprias que requerem conhecimentos específicos por parte de quem planeja, educa e coordena, mas consideramos que, tanto na modalidade presencial como a distância, o conhecimento se relaciona com as experiências pessoais e sociais do sujeito e sua interação com o meio. Contudo, embora a EAD dê aporte para novas possibilidades, não significa que estas serão exploradas na sua integralidade, tendo em vista uma cultura já impregnada no meio estudantil e acadêmico, moldando o processo. Extrapolando o raciocínio construtivista através dos novos meios tecnológicos, próprios da lógica de uma educação construtivista por intermédio da EAD, nos inspiramos em McLuhan (1972) para melhor compreendermos em que nível podemos pensar em uma estrutura educativa que acarrete efetiva mudança no paradigma social. O autor descreve uma nova sociedade integrada por tecnologias da informação, onde o mundo todo se tornaria uma espécie de aldeia global, na qual todos poderiam se comunicar com todos na medida de suas necessidades e vontades.

Podemos aqui criar uma relação entre este novo molde social e o processo de ensino-aprendizado que temos assistido. O professor iluminado que ensina ao aluno inculto é uma concepção de uma sociedade que admite um centro intelectual (o professor) e uma periferia sem voz (o aluno) que deve assimilar o conhecimento do 
centro. No entanto, um modelo de educação a distância via internet, com interação entre os envolvidos, a partir da qual o conhecimento individual se constrói socialmente, pode ser colocado numa nova forma social, na qual a mídia eletrônica, que possibilita uma comunicação mais fluida entre todos, pode gerar uma postura na qual os estudantes não são mais a periferia do conhecimento, e sim geram conhecimentos interagindo.

Além do aspecto hierárquico que os atores assumem dentro de uma escola de ensino convencional, existem ainda os aspectos geográficos que não podem ser ignorados. Um estudante (de escola de ensino convencional), que vive numa pequena cidade do interior, está mais longe de ser um produtor e difusor de conhecimento e informação do que um estudante de um grande centro. A EAD pode romper com esta afirmação, a partir do momento em que torna ambos iguais perante a possibilidade de produção, difusão e acesso ao conhecimento.

A partir da flexibilidade temporal e espacial que a modalidade EAD oferece, pode-se afirmar ser possível levar os cursos lato sensu das universidades para um público cada vez maior, por meio da transposição parcial ou mesmo da replicação total desses cursos no ambiente virtual. Este novo público-alvo contemplado pelas características da EAD teria, como principais demandas atendidas, a flexibilidade de tempo (necessária para trabalhadores muito atarefados) e a mobilidade quase irrestrita do estudante, podendo este fazer seu curso a partir de um local distante do local onde o curso é ministrado. Todavia, conforme Azevedo (2000), é importante notar que existe uma certa resistência na sociedade frente aos cursos a distância, resistência que vem sendo gradativamente vencida pela qualidade que vários destes cursos vêm demonstrando. Nosso estudo apresenta consonância com a segunda parte da afirmação de Azevedo, ao mostrar que, na Instituição analisada, a visão de que a EAD é inferior ao ensino tradicional - embora permeada por críticas - não é mais aceita como verdade por aqueles que já participaram de um curso nesta modalidade.

Considerando a percepção dos próprios alunos acerca da qualidade progressiva do curso analisado, crê-se que futuras edições de cursos de especialização nesta Instituição poderão oferecer maior qualidade, em função da experiência acumulada pelos diversos profissionais envolvidos, e da institucionalização das novas tecnologias e processos. Entretanto, há que se considerar e melhorar diversos aspectos: o relacionamento com a Universidade; a flexibilidade do modelo; a distância transacional, dentre outros. Uma das características necessárias para gerar uma menor distância transacional é gerar um adequado apoio (via cronograma e regras bem definidas, por exemplo), para obter maior autonomia de aprendizado, já que o estudante não é e não deve ser tão dependente do professor, da sala de aula ou de recursos que deve buscar pessoalmente.

Finalmente, em síntese, os resultados do estudo indicam diferentes perspectivas e desafios a serem superados, no desenvolvimento de cursos na modalidade de EAD, mormente nos de grande porte, destacando-se os relacionados: à importância da portabilidade e da interatividade de uma plataforma de EAD, bem como de um serviço de helpdesk rápido e funcional; à potencialidade das interações via chat e fórum na discussão de temas, cada qual com papel próprio; às facilidades de estudar que a nova modalidade de ensino proporciona, com praticidade e qualidade, possibilitando a ampliação e maior democratização do ensino; à exigência de um comportamento de maior autodisciplina dos alunos, e maior atuação individual e proativa; à necessidade de planejamento e boa organização do curso, com currículo bem planejado e estruturado; à importância de manter-se um bom relacionamento entre alunos e instituição, com regras e funcionamento claros, bem como papéis bem definidos para cada um; à identificação de estratégias que melhorem o processo de desenvolvimento e conclusão das 
monografias de final de curso; à necessidade de melhorar as tecnologias e soluções, de produzir diferentes e melhores materiais de aprendizagem, com mais qualidade; e, enfim, à necessidade de estabelecer um novo papel para os educadores.

\section{Referências}

AZEVEDO, W. Panorama atual da educação a distância no Brasil, 2000. Disponível em: < http://www.revistaconecta.com/conectados/wilson_seminario.htm>. Acesso em 10 ago. 2011.

BARDIN, L. Análise de Conteúdo. Lisboa: Edições 70, 1977.

CARDOSO, F. C.; PESTANA, T. M. P. Treinamento online (e-learning). In: BOOG, G. G. (Coord.). Manual de treinamento e desenvolvimento. São Paulo: Makron, 2001. p. 205-220.

CASTELLS, M. A sociedade em rede. São Paulo: Paz e Terra, 1999.

KLERING, L.; BIANCAMANO, M., GUADAGNIN, L. Educação a distância para gestores locais: potencialidades e desafios. In: Congresso Internacional de Educação a Distância da ABED - Associação Brasileira de Educação a Distância, 11, 2004, Salvador. Anais eletrônicos... São Paulo: ABED, 2004. Disponível em: <www.abed.org.br/congresso2004/por/pdf/162-TC-D3.pdf〉. Acesso em: 10 ago. 2011.

KLERING, L.; SCHROEDER, C. Desenvolvimento de uma Plataforma Virtual de Aprendizagem: uma contribuição conceitual e tecnológica, do campo da Administração, à educação a distância. In: XXXII ENANPAD: Encontro Anual da ANPAD - 2008. Anais... Rio de Janeiro: CD-ROM do XXXII da ENANPAD, 2008.

KRAMER, E. A. W. C. (Coord.). Educação a Distância: da teoria à prática. Porto Alegre: Alternativa. 1999.

LOYOLLA, W.; PRATES, M. Ferramental pedagógico de educação a distância mediada por computador (EDMC). Brasília: ABED, 2001. Disponível em: < http://www2.abed.org.br/visualizaDocumento.asp?Documento_ID=51>. Acesso em: 10 ago. 2011.

MAIA, C.; MATTAR, J. ABC da EAD: a educação a distância hoje. São Paulo: Pearson Prentice Hall, 2007.

McLUHAN, H. M. A galáxia de Gutenberg: a formação do homem tipográfico. São Paulo: Companhia Editora Nacional, 1972.

MOORE, M. G. Theory of transactional distance. In: KEEGAN, Desmond (Ed.). Theoretical principles of distance education. London and New York: Routledge, 1993. p. 22-39.

MORAN, J. M. O que é educação a distância, 2002. Disponível em: <http://www.eca.usp.br/prof/moran/dist.htm>. Acesso em: 10 ago. 2011.

PALLOFF, R. M.; PRATT, K. Construindo comunidades de aprendizagem no ciberespaço. Porto Alegre: Artmed, 2002.

PIAGET, J. A equilibração das estruturas cognitivas. Rio de Janeiro: Zahar Editores, 1976.

PIAGET, J. Estudos Sociológicos. Rio de Janeiro: Forense, 1973.

PIAGET, J. Psicologia da inteligência. Rio de Janeiro: Zahar Editores, 1977.

TAPSCOTT, D. Economia digital. São Paulo: Makron Books, 1997.

TAROUCO, L. Educação a distância: Tecnologias e métodos para implantação e acompanhamento. In: WORKSHOP INTERNACIONAL SOBRE EDUCAÇÃO VIRTUAL - WISE'99, 1999, Fortaleza. Anais... Fortaleza: WISE, 1999. p. 344-359.

TOFFLER, A. Powershift: as mudanças do poder. Rio de Janeiro: Record, 1995.

VYGOSTKY, L. A formação social da mente. São Paulo: Martins Fontes, 1988. 2.ed.

VYGOSTKY, L. Pensamento e linguagem. São Paulo: Martins Fontes, 1987. 1.ed. 